\title{
Unraveling the Bacterial Assisted Degradation Pathway of Morpholine- a Xenobiotic Micropollutant: A Sustainability for Zero Pollution Environment
}

Rupak Kumar ( $\nabla$ rupakraman@gmail.com )

CDSCO, New Delhi https://orcid.org/0000-0001-6929-9176

\section{Suman Kapur}

BITS Hyderabad: Birla Institute of Technology and Science - Hyderabad Campus

Srinivasa Rao Vulichi

BITS Hyderabad: Birla Institute of Technology and Science - Hyderabad Campus

\section{Research Article}

Keywords: Morpholine, Xenobiotic, Micropollutant, Recalcitrant, Glycolic route, Ammonia

Posted Date: October 28th, 2021

DOI: https://doi.org/10.21203/rs.3.rs-1008135/v1

License: (c) (i) This work is licensed under a Creative Commons Attribution 4.0 International License. Read Full License 


\section{Abstract}

Biodegradation is the process by which chemicals both natural and xenobiotics are metabolized by microorganisms. Most naturally occurring chemical compounds are biodegradable while xenobiotic may be biodegradable, persistent or recalcitrant. Xenobiotic chemicals, because they are manmade and have developed recently, are present in the environment for comparatively shorter periods of time from its geological presence. This in turn means that the microbial communities present in these environments may not have evolved specific mechanisms for their degradation. Morpholine, a known xenobiotics micropollutant initially believes to be recalcitrant but later prove to be biodegradable by specific set of bacterium species most likely Mycobacterium and Pseudomonas sp in particular. However, the metabolic pathways involved in the successful biodegradation of morpholine stand challenging to establish because of its extreme water solubility and the lack of any chromophore group in morpholine which does not allow easy extraction process. Consequently, no tool for direct estimation of intermediates or metabolites of morpholine has been well reported and only indirect strategies have been developed like presence of microbial growth on intermediates, chemical/analytical assay for intermediate and ammonia measurements to elucidate the degradation pathway for zero pollution environment.

In this present study degradation pathway has been ascertained by some selected bacterial isolate for their capacity to degrade morpholine. Based on the said analysis of culture filtrate, it has been revealed that the isolate namely Halobacillus utilizes glycolic route of the metabolic degradation pathway of morpholine and supports the fact that in presence of morpholine, one of two branches of morpholine biodegradation pathway namely ethanolamine and glycolate was was induced while the other branch was inhibited. Whatever the degradation pathway of morpholine exhibited by bacteria, ammonia is the end product of degradation which would be biochemically utilized by isolate.

\section{Introduction}

Environmental pollution in any form causes foremost peril to the ecosystem and many health hazards. Industrialization, urbanization, exploration of natural resources and technological advances are some of the major contributors to release various anthropogenic chemicals like xenobiotics, plasticizers, pesticides, hydrocarbons, detergents, pharmaceuticals etc to air, water and soil. In general, these chemicals are pollutants and organic in nature and may be behave as biodegradable (transformed by biological mechanisms which might lead to mineralization), persistent (fail to undergo bioremediation in an environment or under specific set of experimental conditions) or recalcitrant (inherently resistant to biodegradation) (Fig. 1). However, most naturally occurring (or biogenic) compounds are biodegradable.

Morpholine (1-oxa-4-azacyclohexane) is one such heterocyclic xenobiotic compound with physical feature of oiliness, volatility and hygroscopic whereas chemically characteristic amine smell and is completely miscible with water as well as with many organic solvents. It has extremely versatile application in different industrial purposes like rubber vulcanization, corrosion control (plating industry), the synthesis of many drugs and personal care products, crop protection agents, glazing agent for coated fruits and 
vegetables, solvent for lyocell process (textile industry), optical brightener (paper industry). Consequently to its wide range of applications, significant amount of morpholine and its salts is released via different industrial process into the environment where its secondary amine functionality leads to nitrosation to form N-nitrosomorpholine (NMOR), a well-characterized carcinogen [1, 2] (Fig. 2).

The large-scale industrial usage and its potentially carcinogenic effects thus have environmental interest for its biodegradation to allow industrial effluents to be disposed of without unacceptable damage to the natural environment by utilizing beneficial and effective microbes for a sustainable remediation. Morpholine was earlier thought to be recalcitrant but later several microbes have been explored to be metabolically able to degrade it. Most of the reported studies showed that Mycobacterium and Pseudomonas sp. are the two potential bacterial isolates that utilize morpholine for their sole source of carbon, nitrogen and energy and hence underwent degradation $[3,4,5]$.

\section{Explore the degradation pathway for sustainable remediation of morpholine}

Nature friendly microbial system has been revolved for the remediation of many pollutants, waste, spill and effluents etc. through the route of biodegradation. Many possible mechanisms exist which differs with different xenobiotics. Some enzymes can bind analogous to their natural substrates which contain xenobiotic functional groups, if these do not greatly alter the change of the active site. So, it is necessary for the enzyme to catalyze a reaction with the xenobiotic as substrate. The success of this reaction metabolism (as a biodegradation mechanism) depends on other factor also, such as the ability of the xenobiotic to act as an inducer and the nature of product/intermediate formed. In specific to morpholine, the metabolic degradation pathway has been very difficult to establish, because of the technical limitation discussed above.

A few studies were carried out to understand the morpholine biodegradation pathway. In these studies, authors have established that for the complete mineralization of morpholine, a hypothetical pathway had been proposed that could proceed via 2-(2 aminoethoxy) acetate to enter either ethanolamine (called pathway 1 ) or glycolate (called pathway 2 ) route of degradation $[6,7]$. Depending on the available morpholine concentration in the cultural medium, one pathway could be used while the other may be inhibited. They further illustrated that degradative pathway might be starts with the first step of the cleavage of the $\mathrm{C}-\mathrm{N}$ bond; this leads formation of an intermediary amino acid, which is further followed by deamination and oxidation of this amino acid to a diacid.

In brief, degradation of morpholine is likely to begin by the breakage of a bond between the hetero atom and an adjacent carbon atom by the enzyme morpholine monooxygenase, responsible for the ring cleavage. Morpholine monooxygenase is an important enzyme in morpholine degradation as this enzyme catalyzes the biotransformation of morpholine to 2-(2-aminoethoxy) acetic acid and contains a cytochrome P450 catalytic subunit $[\mathbf{1 , 6 ]}$. Knapp et al [8] showed that morpholine could serve as substrates for flavin-containing monooxygenase or cytochrome P450 which is associated with oxygen consumption. Poupin et al [9] further, attributed the inhibitory effects of metyrapone on the degradation 
ability of Mycobacterium strain RP1 to prove the involvement of cytochrome P-450 in the bio-degradation of morpholine.

Many different species of Mycobacterium have been shown to degrade morpholine via this shared group of degradation reactions with little information of other enzymes involved in the reactions. Swain et al [10] found proposed hypothetical pathway in Mycobacterium chelonae (Fig. 3). Mazure and Truffaut 1994 described the degradation of morpholine via the ethanolamine and glycolate routes in $M$. aurum MO1.

Recently, a new approach, in which ${ }^{1} \mathrm{H}$-NMR spectroscopy and ion spectroscopy have been performed directly with cultural filtrate to identify some metabolic intermediates of morpholine degradation by $M$. aurum M01 [4, 11] (Fig. 4). Furthermore, the byproducts of microbial processes can provide indication for successful bioremediation process. Since, only hypothetical pathways have been proposed, limited interpretations of various experimental designs have been made (in material method section) to establish the degradation pathway by an isolate to check either it follows an ethanolamine and/or glycolate route for the complete removal of morpholine at lab scale.

\section{Materials And Methods}

\section{Environmental Samples}

The sample used in the present degradation study was collected from natural sources (soil) in and around Durgapur Steel Plant (DSP), West Bangal (WB), India. The site is in the location of Durgapur of latitude $51^{\circ} 50^{\prime} 43.8^{\prime \prime}$ north and longitude $8^{\circ} 16^{\prime} 35.8^{\prime \prime}$ west in the state of WB, India. Soil samples consisted of blackish fine to medium sub-angular gravel in the upper surface including fine sand and a high content of iron flecks. Samples were collected in a clean, sterile plastic container, transferred to the laboratory and stored at room temperature until further use for analysis.

\section{Chemicals and Reagents}

All chemicals and reagents were of analytical grade and were used as received without any further purification from local manufacturer, India. Milli-Q water (Elix 3, conductivity $0.12 \mathrm{mho}$ ) was used in the preparation of aqueous solution of reagents. However autoclaved double distilled water was used for microbial culture purposes.

\section{Screening, characterization and sequence accession of morpholine degrading isolate}

For the initial isolation and cultivation of bacteria, $10^{-10}$ fold serial diluted samples were spread onto nutrient agar (NA) plates. NA plates were prepared according to manufacturer's instruction. Specific colonies obtained were sub-cultured further to find the pure bacterial colony. The selected pure bacterial isolate was identified based on morphological and molecular characterization. Morphological characterization was achieved by visual observation of colony in term of appearance, shape, color, arrangement, and motility by standard staining procedure and check growth in selected media (Hichrome M1353). Further, the pure colony was then identified by 16s rRNA analysis. In order to verify the 
phylogenetic affiliation of the selected isolate, a single colony was collected for DNA isolation (InstaGeneTM Matrix Genomic DNA isolation kit (Bio-Rad Catalog \# 732-6030) as per the kit instruction and procedure) and subjected to Polymeric Chain Reaction (PCR) analysis using primers targeting the $16 \mathrm{~s}$ rRNA gene [27F (AGAGTTTGATCMTGGCTCAG) and 1492R (TACGGYTACCTTGTTACGACTT)]. PCR (20 $\mu \mathrm{L}$ ) contained $8 \mu \mathrm{L}$ of Taq DNA Polymerase Master Mix, $1 \mu \mathrm{L}$ each of $10 \mu \mathrm{M}$ stock 27F/1492R primers, 9 $\mu \mathrm{L}$ DDW and $1 \mu \mathrm{L}$ DNA template. PCR (MJ Research Peltier Thermal Cycler; Bio-Rad PTC 200) reaction was performed using following conditions as per Rahamat Unissa et al [12]. DNA was denatured at $94^{\circ} \mathrm{C}$ for $5 \mathrm{~min}$, followed by $35 \mathrm{cycles}$ of amplification, each of $94^{\circ} \mathrm{C}$ for $45 \mathrm{sec}$ (denaturation), $55^{\circ} \mathrm{C}$ for $60 \mathrm{sec}$ (annealing) and $72^{\circ} \mathrm{C}$ for $60 \mathrm{sec}$, (extension) followed by $10 \mathrm{~min} 72^{\circ} \mathrm{C}$ (final extension). The PCR product was sequenced (by Yaazh Xenomics, Chennai, Tamilnadu, India) and the 16s rRNA sequence was blast using NCBI blast search tool. The phylogeny analysis of the sequence with the closely related sequence of blast results was performed by multiple sequence alignment. The program MUSCLE 3.7 was used for multiple alignments of sequences [13]. The resulting aligned sequences were cured using the program Gblocks $0.91 \mathrm{~b}$. This Gblocks eliminates poorly aligned positions and divergent regions (removes alignment noise) [14]. Finally, the program PhyML 3.0 aLRT was used for phylogeny analysis and HKY85 as substitution model.

The nucleotide sequence of the isolated bacterium was deposited in GenBank, NCBI and was assigned the accession number having 2 letters and 6 numerals. [15].

\section{Cultivation and acclimatization of isolate: Natural selection against morpholine}

Bacterial inoculums were prepared by transferring the selected pure colonies aseptically to $10 \mathrm{ml}$ enrichment media called Knapp buffer or mineral salt solution (MSS) having $\mathrm{KH}_{2} \mathrm{PO}_{4}=100 \mathrm{mg}, \mathrm{K}_{2} \mathrm{HPO}_{4}=$ $100 \mathrm{mg},\left(\mathrm{NH}_{4}\right)_{2} \mathrm{SO}_{4}=100 \mathrm{mg}, \mathrm{MgSO}_{4} \cdot 7 \mathrm{H}_{2} \mathrm{O}=4 \mathrm{mg}$ and $\mathrm{FeCl}_{3}=0.2 \mathrm{mg}$ supplemented with $0.1 \%$ morpholine as described by author itself earlier [16]. Culture tubes were incubated at $37^{\circ} \mathrm{C}$ and $150 \mathrm{rpm}$ for 1-2 weeks and absorbance at $600 \mathrm{~nm}$ was taken at different time points as a measure of growth. Based on the growth, when an optical density (OD) of 0.5 was reached (data not shown), a 1:100 dilution of culture was made with Knapp buffer and diluted culture was further spread on MSS Agar (amended with $2 \%$ Agar $+0.10 \%$ morpholine) to confirm the adaptation of isolate against morpholine stress. Further, the growing culture was centrifuged at $6500 \mathrm{rpm}$ for $10 \mathrm{~min}$ and pellet was re-suspended in the Knapp buffer with gradual increase concentration of morpholine (at an interval of $0.01 \%$ ) up to $0.20 \%$. These were called as seeded acclimatized bacterial inoculums. For each increased acclimatization study, the tested bacteria were grown in MSS broth supplemented with increased concentration of morpholine and respective MSS Agar plate with same concentration of morpholine to confirm the acclimatization against increased morpholine concentration.

The acclimatized inoculums was later grown in presence of intermediate degradative product of morpholine to inspect the fact that this particular isolate either follows pathway 1 or 2 . This can be further validated by performing in-vitro chemical and analytical assay of intermediate product of morpholine degradation in culture filtrate. Lastly, estimation of ammonia/ammonical nitrogen in cultural filtrate has 
been carried out to draw a conclusion for the complete degradation of morpholine by this isolate following the concern pathway.

\section{Growth and Chemical tests of different hypothetical degradation intermediate compounds}

The growth of isolate on various substrates (intermediate degradation products) was investigated by adding the corresponding compounds $(0.15 \%)$ to MSS. The $\mathrm{pH}$ of the medium was adjusted to 7 and growth was carried out at $37^{\circ} \mathrm{C}$ and $150 \mathrm{rpm}$ for 48 hours in triplicate test tubes. At different time points absorbance was measured in term of OD (optical density) to establish that these degradation products might be formed and if so, it would support the growth of the isolated bacteria in their presence.

Chemical tests of degradation products mainly monoethanolamine (primary amine) and morpholine (secondary amine) were carried out by standard Simon- 1 (Rimini test) and Simon-2 (modified Rimini test) respectively to distinguish primary and secondary amine [17] in culture filtrate. The assay is based on the fact that amine undergoes nucleophilic addition reaction with nitroprusside in presence of acetaldehyde or ketone to give a characteristic color of blue and violet in case of primary and secondary amine respectively.

\section{Gas Chromatography (GC) and Mass spectroscopy (MS) studies of degradation intermediate/s}

A GC system (Shimadzu GC-2010) equipped with standard oven, injection ports, flame ionization detector (FID) and column RTX-35 (30 mm x $0.32 \mathrm{~mm} \times 1 \mu \mathrm{m}$ film thickness) with nitrogen as carrier gas by direct injection at split condition has been used for analysis of monoethanoline (MEA). The analytical parameters for analysis of monoethanolamine was summarized in Table 1 as per method (modified with change in column and its parameter) reported by Gerster FM et al [18]

Standard solution of MEA of 0.125 to $0.5 \%$ (prepared in methanol) was injected along with processed culture supernatant (1:10 with methanol) as per method developed below. GC of test samples was run against media blank and positive control to estimate the presence of monoethanolamine in the culture filtrate (discuss elsewhere in the manuscript) by analyzing the area under curve (AUC), given by the machine.

Table $1 \mathrm{GC}$ parameters for the estimation of monoethanolamine 


\begin{tabular}{|c|c|}
\hline Parameters & Specificity \\
\hline Column and its configuration & RTX-35 30m x 0.32mm x $1 \mu \mathrm{m}$ \\
\hline \multirow[t]{5}{*}{ Oven/Column temperature } & Initial $60^{\circ} \mathrm{C}$ \\
\hline & Hold: 1 min \\
\hline & Ramping rate: $30^{\circ} \mathrm{C} / \mathrm{min}$ \\
\hline & Final tem: $240^{\circ} \mathrm{C}$ hold for 3 minutes \\
\hline & Linear velocity: 37.6 cm/sec (for nitrogen) \\
\hline \multirow[t]{3}{*}{ Injector port } & Temperature: $200^{\circ} \mathrm{C}$ \\
\hline & Split Ratio: 30:1 \\
\hline & Injection Volume: $1 \mu$ l \\
\hline Carrier gases & Column Gas Flow: $2 \mathrm{ml} / \mathrm{min}$ \\
\hline \multirow[t]{4}{*}{ (Mobile Phase) } & Purge Flow: $1 \mathrm{ml} / \mathrm{min}$ \\
\hline & Hydrogen: $40 \mathrm{ml} / \mathrm{min}$ \\
\hline & Zero air: $400 \mathrm{ml} / \mathrm{min}$ \\
\hline & Nitrogen: $15 \mathrm{ml} / \mathrm{min}$ \\
\hline Stationary phase & 60\% Dimethyl polysiloxane and $35 \%$ Diphenyl polysiloxane \\
\hline Detector & Flame ionization detector@300C \\
\hline Analysis time & $10.0 \mathrm{~min}$ \\
\hline Software & GC solution \\
\hline Workstation & Window 8 \\
\hline
\end{tabular}

MS system of an integrated LCMS (Liquid Chromatography Mass Spectroscopy) instrument (Shimadzu LCMS-2020) equipped with inlet interface, ion source, mass analyzer and detector has been used for analysis of degradation products of morpholine based on their $\mathrm{m} / \mathrm{z}$ peak. The analytical parameters for estimation of morpholine degradation product are summarized in Table 2.

Table 2 MS operating parameters for intermediate/s 


\begin{tabular}{|c|c|}
\hline Parameter & Specificity \\
\hline \multirow[t]{2}{*}{ Ionization } & electron spray ionization ESI \\
\hline & Needle voltage $4.5 \mathrm{kv}$ \\
\hline Interface temperature & $350^{\circ} \mathrm{C}$ \\
\hline Heat block temperature & $200^{\circ} \mathrm{C}$ \\
\hline Sheath/Drying gas flow rate & $15 \mathrm{l} / \mathrm{min}$ \\
\hline The nebulizer gas flow rate & $1.5 \mathrm{l} / \mathrm{min}$ \\
\hline Acquisition time & $2 \min$ \\
\hline \multirow[t]{4}{*}{ Acquisition mode } & Positive/Negative \\
\hline & Scan m/z 50-200 \\
\hline & Scan speed 52 unit/sec \\
\hline & Sampling acquisition time $1.56 \mathrm{~Hz}(640 \mathrm{msec})$ \\
\hline Detector & Electron multiplier \\
\hline Software & Lab solutions \\
\hline Workstation & Window 7 \\
\hline
\end{tabular}

Sample for injection was prepared with solvent (with methanol/acetonitrile; 1:10) and without solvent system as per combourieu et al [4]. Culture sample (5 ml) was centrifuged at 10,000 rpm for $10 \mathrm{~min}$ and supernatant was filtered through $0.22 \mu \mathrm{m}$ pore size nylon filter (Axiva Sichem Biotech, India) to avoid any bacterial cells. $1 \mathrm{ml}$ neat filtrate (1:10 diluted) was directly used to inject into MS system. Similarly, MSS culture media was also prepared accordingly.

\section{Estimation of ammonia}

The presence of ammonia in culture supernatant was estimated by standard Nessler's method [19]. This method involves the coupling of ammonium to Nessler's reagent to produce a yellow color under strong alkaline condition. A resulting yellow color was formed in proportion to ammonium $\left(\mathrm{NH}^{+}-\mathrm{N}\right)$ concentration and was measured at $425 \mathrm{~nm}$ using an Elisa reader (ELX50/8MS BioTek India) against reagent blank and expressed as $\mathrm{mg} / \mathrm{L}(\mathrm{ppm})$. A standard solution of $10 \mathrm{ppm}$ of $\mathrm{NH} 4^{+}-\mathrm{N}$ were prepared by dissolving $4.773 \mathrm{mg}$ ammonium chloride in $125 \mathrm{ml}$ of double distilled water to make it further dilution to a concentration of 1-5 ppm NH4 $4^{+}-\mathrm{N}$ solution. A calibration curve was plotted and ammonia has been quantified in accordance with standard curve.

\section{Results}

\section{Morphological and Molecular Identification}


The morphological feature of the isolate was found to be white colour, rod shaped, dull opaque appearance, smooth texture and convex elevation. Standard gram staining finds it a gram negative with high motility and also shows growth on selective media of Hichrome M1353.

The primary sequence of the $16 \mathrm{~s}$ rRNA from present bacterial isolate was determined. The program PhyML 3.0 aLRT for phylogeny analysis and HKY85 as substitution model on $16 \mathrm{~s}$ rRNA gene sequences showed the phylogenetic position of this isolate to be a closely related species from the genus Halobacillus blutaparonensis with the sequence representative of E. coli (Fig.5).

Nucleotide sequence accession was assigned by Gene Bank, NCBI, and an accession number namely KC345029 was found to this bacterial isolate of genus Halobacillus blutaparonensis.

\section{Growth on intermediates}

The isolate showed growth in presence of morpholine as well as in intermediate aminoethoxy ethanol (reduced product of aminoethoxy acetate) by taking it as carbon source. However, no growth was recorded in presence of ethanolamine in culture media as shown in Fig. $\mathbf{6}$. The count of bacterial cells was adjusted to $1 \times 10^{8}$ cells $/ \mathrm{mL}$ ( 1 unit absorbance $=5 \times 10^{8}$ cells) by varying incubation period up to 48 hours.

\section{Chemical assay for intermediate/s}

Based on Simon test 1 and 2, the presence of MEA and morpholine in the culture supernatant is shown below in Table 3.

Table 3 Simon test of primary amine (MEA) secondary amine (Morpholine) in culture supernatant 


\begin{tabular}{|c|c|c|c|c|}
\hline Sample & Test & Feature & Remark & Result \\
\hline Morpholine & Simon 1 & Characteristic blue color & & + (Morpholine) \\
\hline Monoethanolamine & Simon 2 & Characteristic violet color & & $+(\mathrm{MEA})$ \\
\hline \multirow[t]{2}{*}{ Culture media } & Simon 1 & No characteristic blue color & & - (Morpholine) \\
\hline & Simon 2 & No characteristic violet color & & - (MEA) \\
\hline \multirow[t]{2}{*}{ Culture Supernatant } & Simon 1 & No characteristic blue color & & - (Morpholine) \\
\hline & Simon 2 & No characteristic violet color & & - (MEA) \\
\hline
\end{tabular}

\section{GC and MS studies of culture filtrate}

GC of culture filtrate was run along with different concentration of standard MEA solution. GC analysis confirms that the proposed compound indicating the retention time ( 2.2 $\mathrm{min})$ is reported to be MEA 
(Table 4). However, absentia of MEA peak in diluted culture filtrate, supporting the fact that this bacterium prefers the glycolic route of degradation of morpholine which was further proven by MS analysis.

MS was run directly with cultural filtrate (with and without solvent). Each sample was performed separately in positive and negative mode (Table $\mathbf{5}$ and Fig.7).

Table $4 \mathrm{GC}$ analysis of the diluted culture filtrate

\begin{tabular}{|llll|}
\hline Vial & Retention Time (min) & Area Under Curve & Compound \\
\hline Methanol & 1.331 & 378534920.9 & Methanol \\
\hline 5000 ppm MEA & 1.333 & 366649701.7 & Methanol \\
& 2.218 & 2748948.5 & Monoethanolamine \\
\hline 2500 ppm MEA & 1.331 & 374551161.2 & Methanol \\
& 2.216 & 2397300.9 & Monoethanolamine \\
\hline 1250 ppm MEA & 1.331 & 378803557.4 & Methanol \\
& 2.211 & 1149593.1 & Monoethanolamine \\
\hline Culture filtate (1:10) & 1.334 & 310947764.4 & Methanol \\
& 2.231 & 92353.6 & No Monoethanolamine \\
\hline
\end{tabular}

Table 5 Expected intermediated in MS analysis of culture supernatant (with/without different solvent)

\begin{tabular}{|c|c|c|c|c|}
\hline Sample & Solvent & $\begin{array}{l}m / z \\
+ \text { mode }\end{array}$ & $\begin{array}{l}\mathrm{m} / \mathrm{z} \\
\text { - } \text { mode }\end{array}$ & Remark \\
\hline \multirow{4}{*}{$\begin{array}{l}\text { Culture filtrate } \\
\text { (with solvent) }\end{array}$} & \multirow[t]{2}{*}{ Acetonitrile } & 121.00 & & {$[\mathrm{M}+2 \mathrm{H}]^{+}$2,2 Amino ethooxy acetic acid } \\
\hline & & & 232.90 & {$[\mathrm{M}-2 \mathrm{H}+2 \mathrm{~K}+\mathrm{Na}]^{-}$Diglycolic acid } \\
\hline & \multirow[t]{2}{*}{ Methanol } & & 75.00 & {$[\mathrm{M}-\mathrm{H}]^{-}$} \\
\hline & & & & Glycolic acid \\
\hline \multirow{2}{*}{\multicolumn{2}{|c|}{$\begin{array}{l}\text { Neat Culture filtrate } \\
\text { (without solvent) }\end{array}$}} & 120.00 & & {$[\mathrm{M}+\mathrm{H}]+2,2$ Amino ethoxy acetate } \\
\hline & & & 133.00 & {$[\mathrm{M}-\mathrm{H}]^{-}$Anion of glycolic acid } \\
\hline
\end{tabular}

It was observed that when culture filtrate dissolved in acetonitrile, two major peaks (chromatogram not shown) has been reported; first pertaining to $\mathrm{m} / \mathrm{z}=121.00$ which indicates the 2,2 aminoethoxy acetic acid (having formula $\mathrm{C}_{4} \mathrm{H}_{9} \mathrm{NO}_{3}$ and molecular weight $=119.119$ ) as $[\mathrm{M}+2 \mathrm{H}]^{+}$and other $\mathrm{m} / \mathrm{z}=232.90$ indicating the diglycolic acid (having formula $\mathrm{C}_{4} \mathrm{H}_{6} \mathrm{O}_{5}$ and molecular weight $=134.09$ ) as $[\mathrm{M}-2 \mathrm{H}+2 \mathrm{~K}+\mathrm{Na}]^{-}$. 
Further, it is also noticed that when methanol is used as a solvent system, a peak of $\mathrm{m} / \mathrm{z}=75$ has been recognized indicates the presence of glycolic acid (having formula $\mathrm{C}_{2} \mathrm{H}_{4} \mathrm{O}_{3}$ and molecular weight $=76$ ) as $[\mathrm{M}-\mathrm{H}]^{-}$which is final degradation product of morpholine. Presence of these fragments in culture filtrate sample (with solvent) indicating the successful degradation of morpholine by bacteria by following the glycolic acid pathway.

However, the $\mathrm{m} / \mathrm{z}$ peak of neat cultural filtrate (without solvent) indicates the presence of 2, 2 amino ethoxy acetate $\left(\mathrm{m} / \mathrm{z}=120.00\right.$ as $\left.[\mathrm{M}+\mathrm{H}]^{+}\right)$and anion of glycolic acid $\left(\mathrm{m} / \mathrm{z}=133.00\right.$ as $\left.[\mathrm{M}-\mathrm{H}]^{-}\right)(\mathrm{Fig} .7)$ which supports the earlier fact that this particular isolate prefer the path of glycolic route (pathway 2) of degradation similar to mycobacterium strain as reported by Combourieu et al [4].

MS analysis also supports the GC findings of no availability of ethanolamine in culture filtrate. Based on this, it is envisaged that ethanolamine might be inhibitory to bacteria. Hence, this bacterial isolate prefers the glycolic route of metabolic pathway with supporting the fact that in presence of morpholine, one of two branches of morpholine biodegradation pathway was induced while the other branch was inhibited.

The illustrated degradative pathway might start with the cleavage of the C-N bond; this leads formation of an intermediary amino acid, which is further followed by deamination and oxidation of this amino acid to a diacid as shown in Fig. 4.

\section{Ammonia release: As end product of morpholine degradation}

Morpholine can be degraded by bacteria, with the liberation of ammonia which can biochemically utilized as a nitrogen source. Whatever the degradation pathway of morpholine, ammonia is the end product.

Based on Nessler quantification, ammoniacal nitrogen produced by isolate is calculated (as shown in the Table 6 and Fig. 8) by the regression equation $\left(y=0.145 x-0.028\right.$ with $\left.r^{2}=0.984\right)$ and found to be $5.2 \mathrm{ppm}$. Initial morpholine concentration in culture supernatant (before degradation) was reported to be $2000 \mathrm{ppm}$. The molar conversion ratio of morpholine to ammonia was found to be 1:0.014. Also, it was shown that the final $\mathrm{pH}$ of the media throughout the experiment did not change supporting the fact that low concentration of ammonia was released as end product of morpholine degradation.

Table 6 Estimation of ammonia by Nessler reagent 


\begin{tabular}{|c|c|c|c|c|c|c|c|}
\hline Well & $\begin{array}{l}\text { 10PPM } \\
\text { Stock } \\
\text { NH4-N+ } \\
(\mu \mathrm{l})\end{array}$ & $\begin{array}{l}\text { Milli Q } \\
\text { water } \\
(\mu \mathrm{l})\end{array}$ & $\begin{array}{l}\text { Culture } \\
\text { Media } \\
(\mu l)\end{array}$ & $\begin{array}{l}50 \% \text { Na-k } \\
\text { Tartarate } \\
(\mu \mathrm{l})\end{array}$ & $\begin{array}{l}\text { Nesserler } \\
\text { Reagent } \\
(\mu \mathrm{l})\end{array}$ & $\begin{array}{l}\text { Absorbance } \\
@ 405 \mathrm{~nm}\end{array}$ & $\begin{array}{l}\text { Net } \\
\text { Absorbance }\end{array}$ \\
\hline Water Blank & - & 250 & - & 5 & 5 & 0.106 & 0 \\
\hline $\begin{array}{l}\text { Media } \\
\text { Blank }\end{array}$ & - & - & 250 & 5 & 5 & 2.630 & 0 \\
\hline $1 \mathrm{ppm}$ & 25 & 225 & - & 5 & 5 & 0.197 & 0.091 \\
\hline $2 \mathrm{ppm}$ & 50 & 200 & - & 5 & 5 & 0.390 & 0.284 \\
\hline 3 ppm & 75 & 175 & - & 5 & 5 & 0.459 & 0.353 \\
\hline $4 \mathrm{ppm}$ & 100 & 150 & - & 5 & 5 & 0.658 & 0.552 \\
\hline $5 \mathrm{ppm}$ & 125 & 125 & - & 5 & 5 & 0.831 & 0.725 \\
\hline $\begin{array}{l}\text { Culture } \\
\text { supernatant }\end{array}$ & 250 & & - & 5 & 5 & 3.355 & 0.725 \\
\hline
\end{tabular}

\section{Discussion}

Based on the result summarized, it has been reported that the isolate prefers to undergo glycolic route of degradation instead of ethanolamine route as it inhibits the bacterial growths. The illustrated degradative pathway might start with the first step of the cleavage of the $\mathrm{C}-\mathrm{N}$ bond; this leads to the formation of an intermediary amino acid, which is further followed by deamination and oxidation of this amino acid to form diacid (Fig. 9) which is metabolically consumed by isolate.

More ever, the presence of other intermediate compounds also supports this finding with a conclusion that the diglycolic route of biodegradation might be a common degradation mechanism shown by other groups of bacteria too. This was well reported by other authors $[4,9,11]$ to prove our finding. Whatever the degradation pathway was exhibited by bacteria, the end product was ammonia which would biochemically use by bacteria. Our studies confirm the presence of ammonia as an end product and the molar ratio of morpholine to ammonia was found to be 1:0.014. Due to the low concentration of ammonia produced, the $\mathrm{pH}$ of the culture media did not change throughout the experiment. However, higher molar ratio of morpholine to ammonia results in the inhibitory effect on the growth of bacteria because it increases the $\mathrm{pH}$ of media to shift it toward alkalinity. The ratio of morpholine to ammonia was found to be different for different strains of bacteria as reported by Magda M.Aly 2011 (1: 0.89 for Mycobacterium sp.) [3], Schrader et al 2000 (1:0.5 for Mycobacterium sp.HE5) [20] and N. Mazure et al 1994 (1: 0.82 for Mycobacterium sp.M01) [21].

\section{Conclusion}


Environmental pollution has become a global problem. Every day, everybody, every sector, every organization/industry is responsible for environmental pollution due to indiscriminate and frequent release of xenobiotics by different anthropogenic activities. Morpholine is one such xenobiotic chemical. The heterocyclic morpholine has versatile application in different industrial setup processing and so it is released into the environment through the differential process of discharge at a micro concentration to macro concentration. It is necessary to highlight that anthropogenic environmental pollutants even at low concentrations often produce deleterious effects on organisms, which are difficult to be predicted because measurable effects are expressed only after prolonged exposure.

In the environment, the majority of morpholine exposure comes through water and leads to form human carcinogen NMOR by the process of natural nitrosation. Also, it is mention to note that this nitrosation process is also carried out in the biological system when it is directly ingested, inhaled, or applied to the skin acting as a mutagen or carcinogen. In addition, NMOR is known to act as a mediator for various debilitating cancers associated with organs like the digestive tract, respiratory tract, kidney, and liver when it biomagnifies through different tropic levels of biota by consumption or in taking of pollutant water and so eventually perturbing into the food-chain.

In this concern, it is better to provide a solution for efficient discharge or effective remediation by costeffective, nature-friendly biological tools powered by microbes to conserve the natural environment and resources, and to curb the negative impacts on biota. This sustainable solution is an ancient core concept (ACC) that continues to be the only solution for healthy and productive life into the distant future. The workhorses of this effective removal are microbes and so it must be explored and elucidate its degradation pathway to know how potent the microbes are for the cleaner, greener, and safer solution to decontaminating a wide range of pollutants and its mitigation.

\section{Declarations}

Conflict of interest The authors undertake that there is no conflict of interest.

Consent for Publication The authors give consent for the manuscript to be published.

Research involving the Human subject/Animal studies No such studies has been conducted in this manuscript.

Ethics committee approval The scope of article does not involve animal/ human subject studies. Hence, no institutional ethics committee approval has been required.

Funding Source I would like to acknowledge my former institute BITS Pilani, Hyderabad Campus, Hyderabad, India for providing the all necessary lab infrastructure and financial support.

Acknowledgements I would like to express my gratitude to my former institute namely BITS Pilani, Hyderabad Campus, Hyderabad, India for providing the technical supports to generate the results. The 
chemical sketches in this manuscript are through the free online version of ChemDraw application is thankfully acknowledged.

\section{References}

1. Sielaff B, Andreesen J, Schräder T (2001) A cytochrome P450 and a ferredoxin isolated from Mycobacterium sp. strain HE5 after growth on morpholine. Appl Microbiol Biotechnol 56(3):458-464. https://doi.org/10.1007/s002530100634

2. Kumar R, Kapur S, Vulichi Srinivasa Rao (2021) \&. A Xenobiotic Pollutant Detection for a Zero Pollution Environment Monograph of the 1st International Conference Strategies toward Green Deal Implementation - Water and Raw Materials, Part-II, 74-90

3. Aly MM (2011) Degradation of morpholine by Mycobacterium sp. isolated from contaminated wastewater collected from Egypt. Afr J Biotechnol 10(42):8351-8358. https://doi.org/10.5897/AJB11.308

4. Combourieu B, Besse P, Sancelme M, Godin JP, Monteil A, Veschambre H, Delort AM (2000) Common Degradative Pathways of Morpholine, Thiomorpholine, and Piperidine by Mycobacterium aurum M01: Evidence from1H-Nuclear Magnetic Resonance and Ionspray Mass Spectrometry Performed Directly on the Incubation Medium. Appl Environ Microbiol 66(8):3187-3193. https://doi.org/10.1128/aem.66.8.3187-3193.2000

5. Schräder T, Schuffenhauer G, Sielaff B, Andreesen JR (2000) High morpholine degradation rates and formation of cytochrome P450 during growth on different cyclic amines by newly isolated Mycobacterium sp. strain HE5The EMBL accession number of the 16S rRNA gene of Mycobacterium sp. strain HE5 is AJ012738. Microbiology 146(5):1091-1098. https://doi.org/10.1099/00221287146-5-1091

6. Shaikh AR, Sahnoun R, Broclawik E, Koyama M, Tsuboi H, Hatakeyama N, Miyamoto A (2009) Quantum chemical studies for oxidation of morpholine by Cytochrome P450. J Inorg Biochem 103(1):20-27 https://doi.org/10.1016/j.jinorgbio.2008.08.013

7. Mazure N, Truffaut N (1994) Degradation of morpholine by Mycobacterium aurum M01. Can J Microbiol 40(9):761-765. https://doi.org/10.1139/m94-120

8. Knapp JS, Emtiazl G, Yusoff S, Heron ST (1996) The utilization of morpholine as a sole nitrogen source by Gram-negative bacteria. Lett Appl Microbiol 23(5):334-338. https://doi.org/10.1111/j.1472-765X.1996.tb00202.x

9. Poupin P, Truffaut N, Combourieu B, Besse P, Sancelme M, Veschambre H, Delort AM (1998) Degradation of morpholine by an environmental Mycobacterium strain involves a cytochrome P-450. Appl Environ Microbiol 64(1):159-165. https://doi.org/10.1128/AEM.64.1.159-165.1998

10. Swain A, Waterhouse KV, Venables WA, Callely AG, Lowe SE (1991) Biochemical studies of morpholine catabolism by an environmental mycobacterium. Appl Microbiol Biotechnol 35(1):110114. https://doi.org/10.1007/BF00180646 
11. Combourieu B, Besse P, Sancelme M, Veschambre H, Delort AM, Poupin P, Truffaut N (1998) Morpholine degradation pathway of Mycobacterium aurum M01: direct evidence of intermediates by in situ $1 \mathrm{H}$ nuclear magnetic resonance. Appl Environ Microbiol 64(1):153-158. https://doi.org/ 10.1128/AEM.64.1.153-158.1998

12. Unissa R, Sudhakar M, Reddy ASK (2015) Screening of marine bacterial cultures for Extracellular production of I-arginine deiminases. World J Pharm Res 4(6):1194-1204

13. Edgar RC (2004) MUSCLE: multiple sequence alignment with high accuracy and high throughput. Nucleic Acids Res 32(5):1792-1797. https://doi.org/10.1093/nar/gkh340

14. Talavera G, Castresana J (2007) Improvement of phylogenies after removing divergent and ambiguously aligned blocks from protein sequence alignments. Syst Biol 56(4):564-577. https://doi.org/10.1080/10635150701472164

15. NCBI Genbank accession number; Retrieved from https://www.ncbi.nlm.nih.gov/Sequin/acc.html

16. Kumar R, Manga P, Gupta S, Kapur S (2014) Biological approaches for treating industrial effluents containing Morpholine. Industrial and Environmental Biotechnology, edited by Krishna Pramanik and Jayant Kumar Patra. Studium Press India Pvt Ltd, New Delhi, PP-255-64, ISBN: 9789380012674

17. Identification of Amines (2014) Retrieved from https://abu.edu.iq/sites/default/files/courses/https\%253A/abu.edu.iq/pharmacy/courses/2/organicchemistry-II-III-Lab/identification_of_amines_8.pdf

18. Gerster FM, Hopf NB, Huynh CK, Plateel G, Charrière N, Vernez D (2012) A simple gas chromatography method for the analysis of monoethanolamine in air. J Sep Sci 35(17):2249-2255.

https://doi.org/10.1002/jssc.201200196

19. Nessler reagent for determination of ammonia and ammonium salts. Retrieved from https://in.vwr.com/store/product/2995414/nessler-s-reagent-for-determination-of-ammonia-andammonium-salts

20. Schräder T, Schuffenhauer G, Sielaff B, Andreesen JR (2000) High morpholine degradation rates and formation of cytochrome P450 during growth on different cyclic amines by newly isolated Mycobacterium sp. strain HE5The EMBL accession number of the 16S rRNA gene of Mycobacterium sp. strain HE5 is AJ012738. Microbiology 146(5):1091-1098. https://doi.org/10.1099/00221287146-5-1091

21. Mazure N, Truffaut N (1994) Degradation of morpholine by Mycobacterium aurum M01. Can J Microbiol 40(9):761-765. https://doi.org/10.1139/m94-120

\section{Figures}




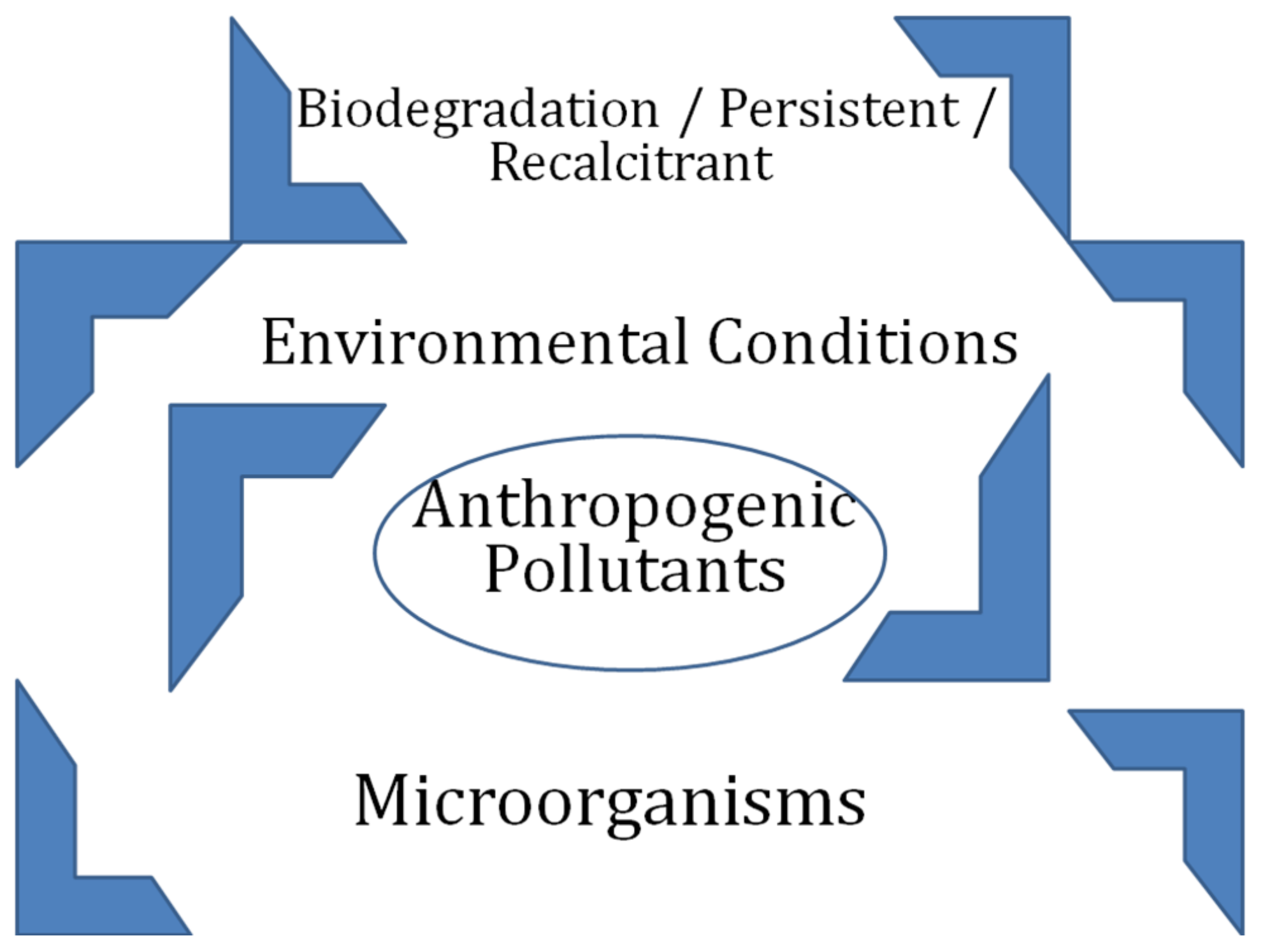

Figure 1

Nature of pollutants of anthropogenic origin

$$
\begin{aligned}
2 \mathrm{HNO}_{2} & \rightleftharpoons \mathrm{N}_{2} \mathrm{O}_{3}+\mathrm{H}_{2} \mathrm{O} \\
\mathrm{N}_{2} \mathrm{O}_{3} & \rightleftharpoons \mathrm{NO}^{+}+\mathrm{NO}_{2}^{-}
\end{aligned}
$$

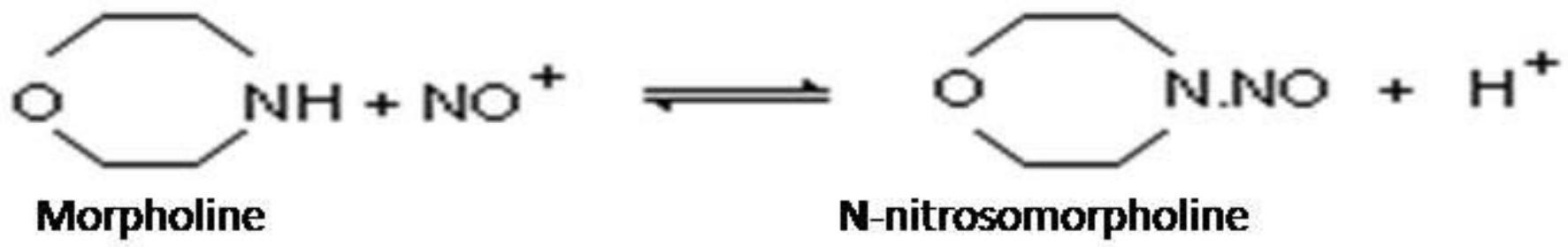

Figure 2 
Formation of NMOR-a potential carcinogen<smiles>C[14CH2]COCC(=O)COCCN</smiles>

Morpholine

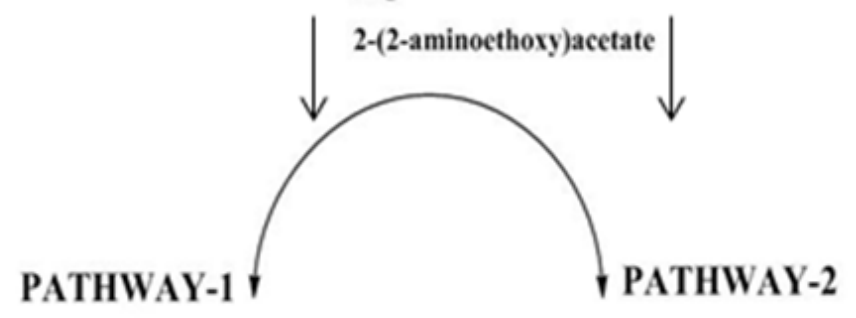<smiles>CC(=O)C=CC(C)C(C)=O</smiles>

Ethanolamine Acetate

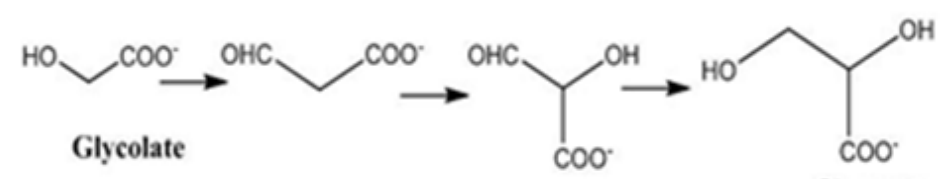

Glycerate

Figure 3

Hypothetical pathway of morpholine degradation where, $X=2$-(2-aminoethoxy) acetaldehyde, $Y=2(2-$ aminoethoxy) acetate and $a, b, c$ indicates the position of carbon in the ring (taken from [10] with the citation)

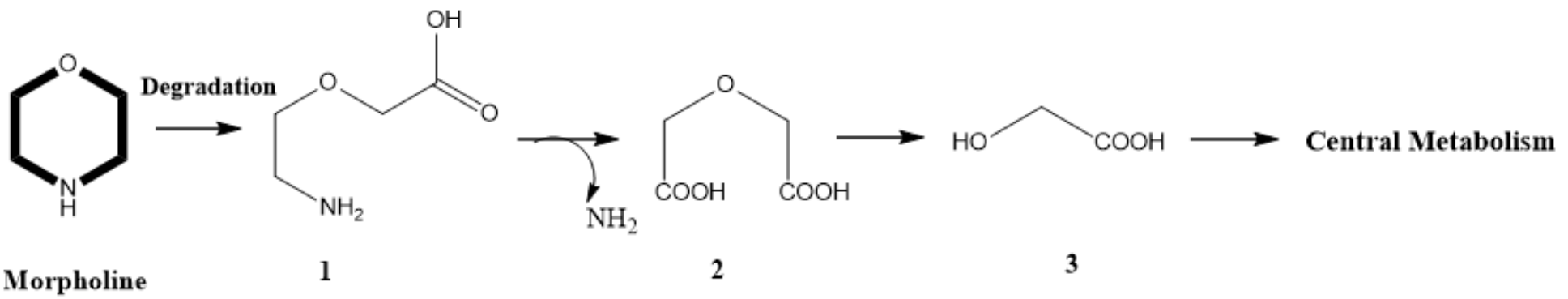

Figure 4

Postulation of morpholine degradation pathway; where 1 represent: 2-(2-aminoethoxy) acetate, 2: diglycolic acid and 3: glycolic acid

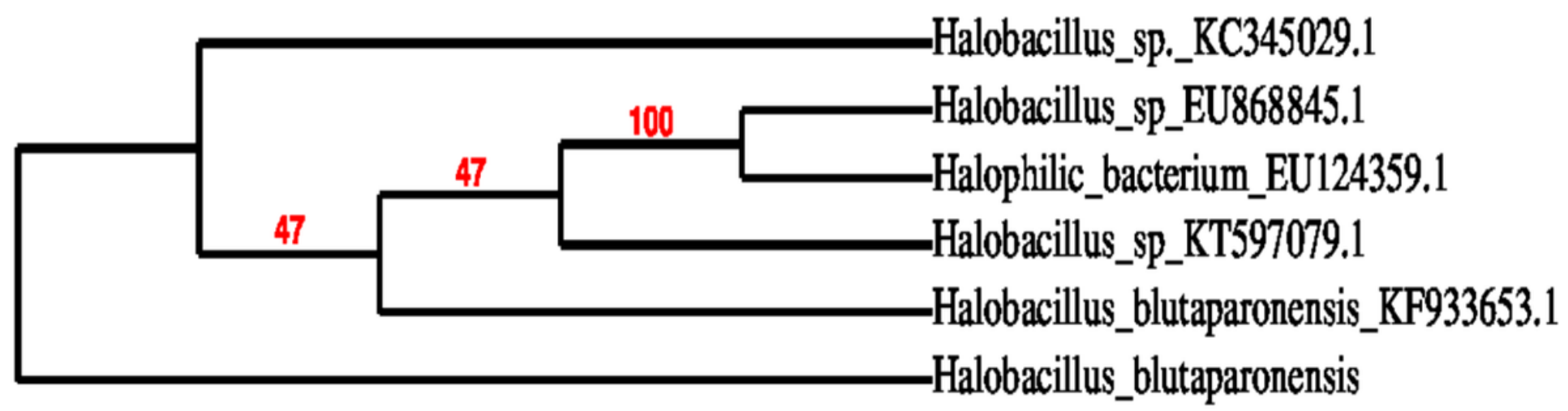


Figure 5

Molecular phylogeny of 16sRNA sequenced and sequences from identified bacteria in the database. The sequence of E.coli served as the out group for rooting the tree.

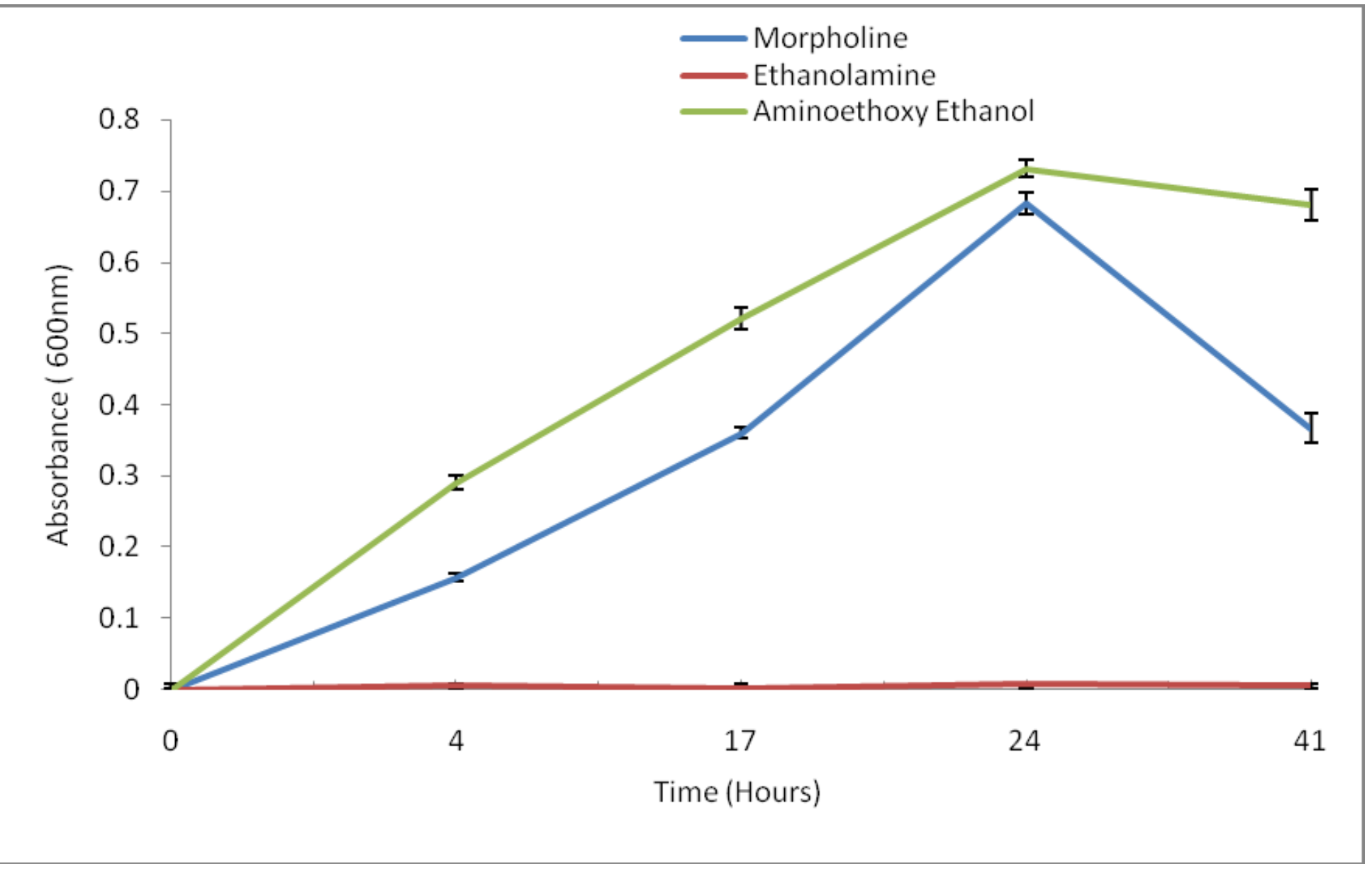

\section{Figure 6}

Growth curve of isolate in presence of intermediates of morpholine degradation 
Line\#:1 R. Time:0.833(Scan\#:51)

RawMode:Averaged 0.667-0.967(41-59) BasePeak:120.10(20044)

BG Mode:Averaged 0.000-0.633(1-39) Segment 1 - Event 1

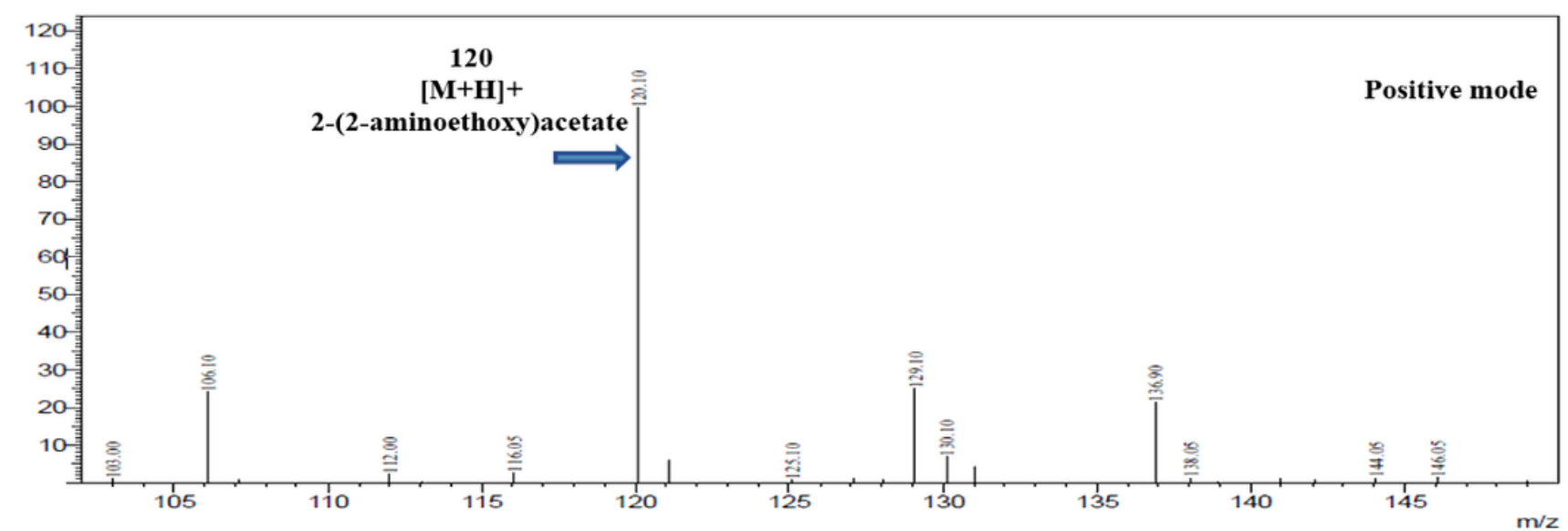

Line\#:2 R. Time:0.983(Scan\#:60)

MassPeaks: 31
RawMode: Averaged 0.683-0.983(42-60) BasePeak: $115.00(3087)$
BG Mode:Averaged 0.017-0.650(2-40) Segment 1-Event 2

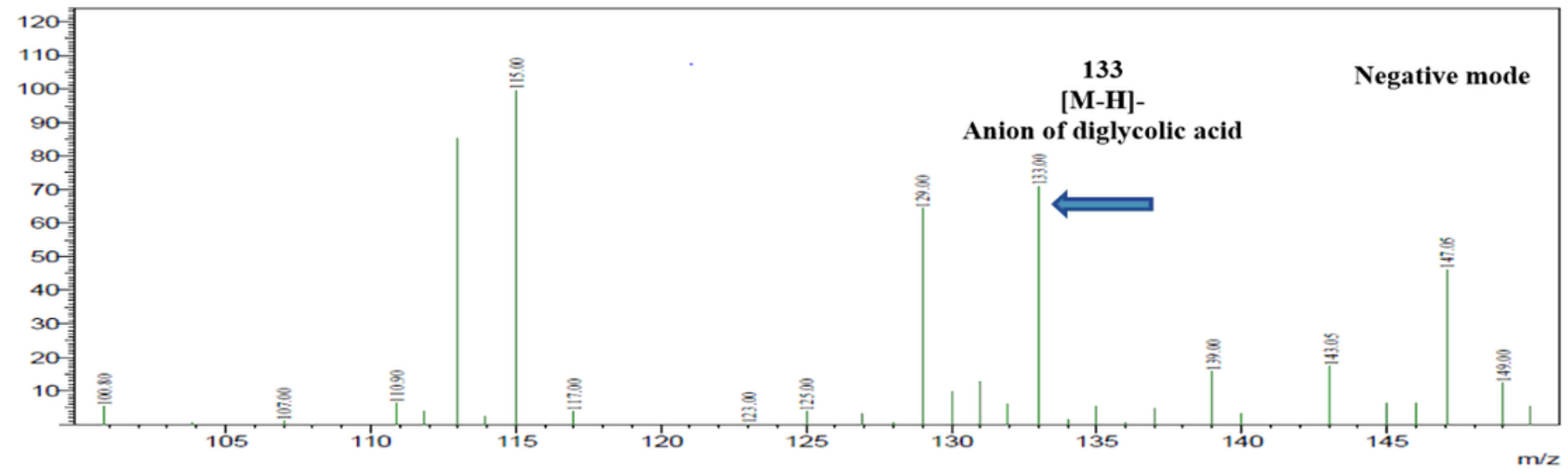

Figure 7

ESI mass spectra recorded under positive and negative ionization of neat culture supernatant 


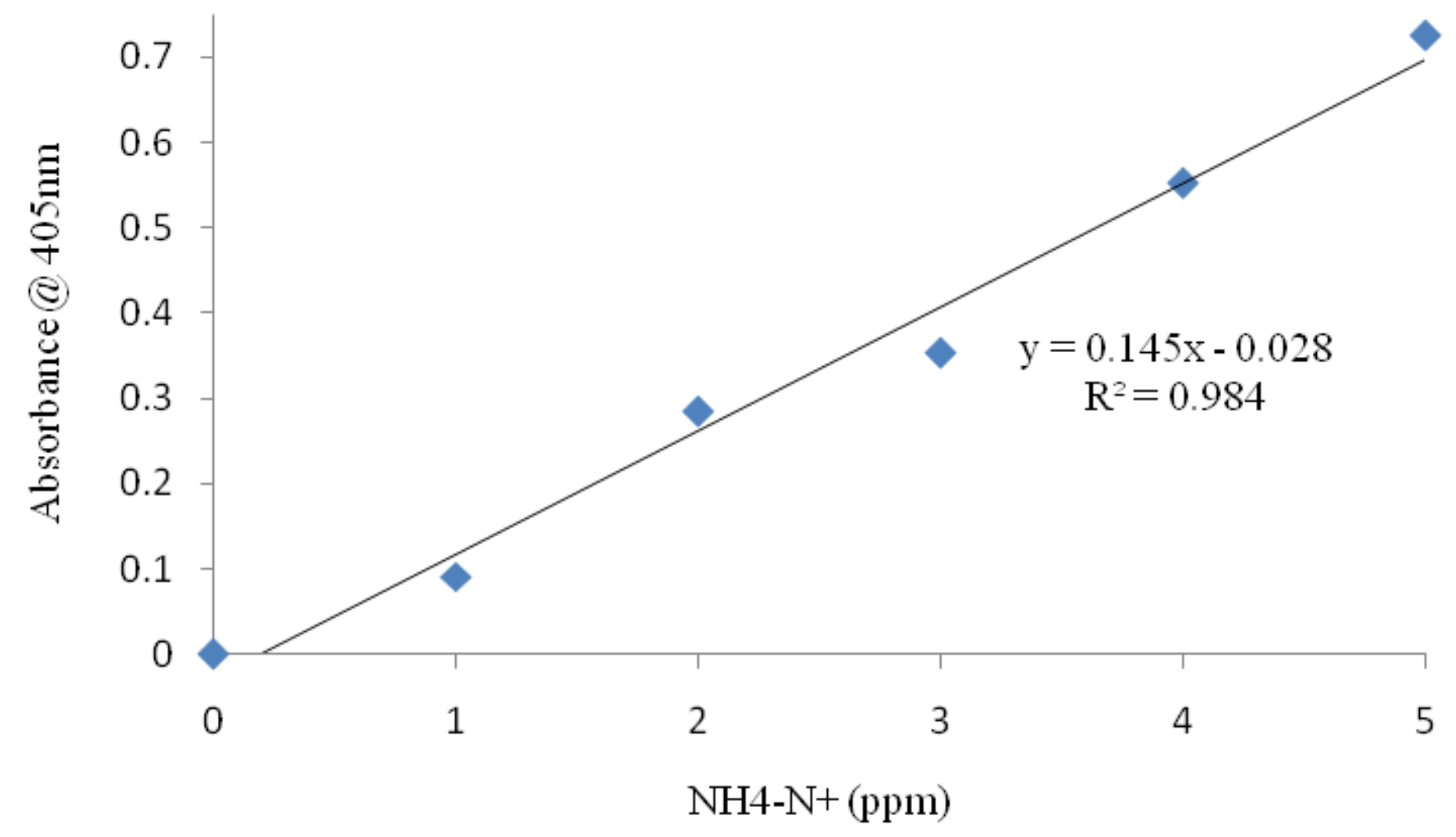

Figure 8

Standard curve of ammoniacal nitrogen by Nessler reagent 

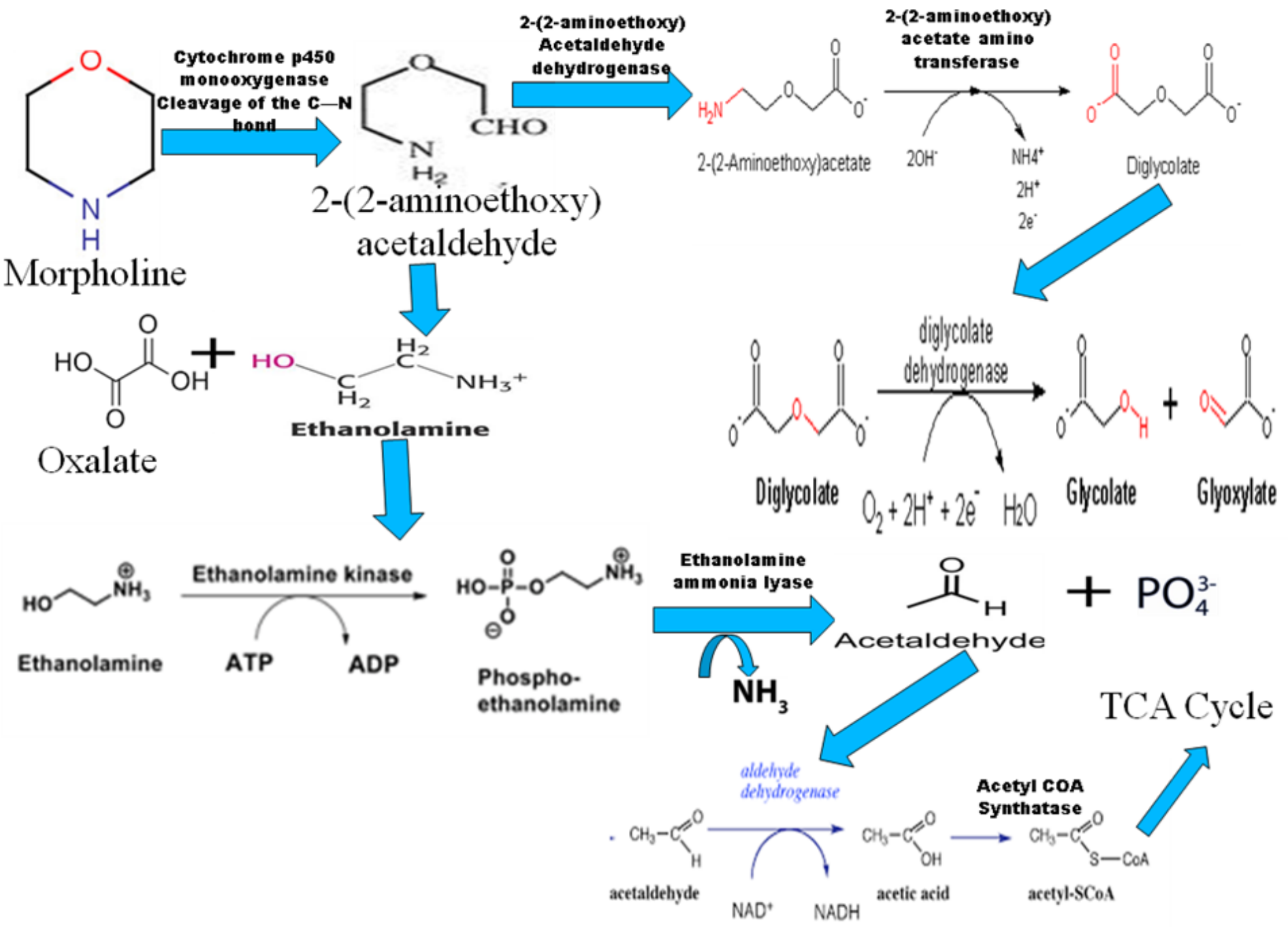

Figure 9

The complete illustration of the degradation pathway of morpholine 